\title{
Mothers and grandmothers of Down's syndrome patients as controls for fra $(X)$ carriers
}

\author{
F. Vogel \\ Institut für Humangenetik der Universität, Im Neuenheimer Feld 328, W-6900 Heidelberg 1, Federal Republic of Germany
}

Received August 15, 1991

Jongbloet questions the usefulness of mothers and grandmothers of Down's syndrome (DS) patients as controls for the fertility of fragile X (fra[X]) carriers (Vogel et al. 1990). He mentions a number of reports from the literature that apparently point to a reduced fecundity that may also result in a certain loss of fertility. Indeed, the assertion that DS mothers have a reduced biological capability is old; it was originally suggested by $\mathrm{H}$. Geyer (1939). It must be admitted that the ideal controls for such a comparative study (ideal in the sense that all other conditions are equal to fra $(X)$ carriers, excepting the fact that the woman is not a fra $(\mathrm{X})$ heterozygote) do not exist. Therefore, some compromise is necessary. Here, mothers and other family members of DS patients appeared to us as the least biased control group that can be used; this is also true from the point of view of prevalence in the population and availability. As Jongbloet (1991) states himself, "not all researches agree on maternal subfecundity in DS mothers". Moreover, at least in advanced populations, the actual number of children (fertility) depends on biological fecundity only in part; birth control, which is socially and psychologically determined, is more important. Furthermore, only a fraction of the women whose fertility was compared were actually mothers of patients (DS or fra[X]). Many of them were more remotely related, viz. grandmothers, sisters, aunts, etc. Does Dr. Jongbloet expect all of them to be reduced in their fecundity? Does he assume, that this reduction explains the large difference in fertility between $\mathrm{fra}(\mathrm{X})$ and DS families that has been shown in our study? This would certainly be too far-fetched an explanation.
Planning this study, my concern was the opposite: because of the well-known increase of the nondisjunction risk with maternal age, mothers of DS patients are, on average, older than mothers of fra (X) patients. However, women giving birth to children at a relatively advanced age are expected to be mothers having, on average, several children. Therefore, our study might be biased in the opposite direction: the actual increase in fertility of fra (X) carriers might be underrated by our comparison.

It is possible that the two biases might cancel each other out. It is my opinion (admittedly not more than an educated guess) that we have slightly underestimated, rather than overrated, the actual reproductive advantage of fra (X) mothers. In the meantime, Sherman et al. (1988) have confirmed higher incidence of (apparently dizygotic) twinning in $\mathrm{fra}(\mathrm{X})$ heterozygotes, a sign of their high fecundity. However, everybody is invited to repeat our study using another family sample and control families regarded as more suitable.

\section{References}

Geyer H (1939) Zur Ätiologie der mongoloiden Idiotie. Thieme, Leipzig

Jongbloet PH (1992) Selective advantage of fra(X) heterozygotes compared with mothers of Down syndrome probands? Hum Genet 88:599-600

Sherman SL, Turner G, Sheffield L, Laing S, Robinson H (1988) Investigation of the twinning rate in families with the fra $(\mathrm{X})$ syndrome. Am J Med Genet 30:625-631

Vogel F, Crusio WE, Kovac C, Fryns J-P, Freund M (1990) Selective advantage of $\mathrm{fra}(\mathrm{X})$ heterozygotes. Hum Genet $86: 25-32$ 